\title{
EDUARDOSUBIRATS \\ Razón y Nihilismo \\ Una introducción a la crítica de la cultura \\ moderna
}

I A genealogía de la razón comprende tanto los aspectos Lintelectuales del conocimiento, como los componentes morales que la acompañan, los valores estéticos que la han definido, su vínculo social - tanto constituyente como constitutivo-, las dimensiones, en fin, del poder, de la organización social y, en particular, la proyección histórica hacia el futuro, que siempre está ligada a ella.

La geneología de la razón se distingue de su análisis o fundamentación metodológica en que, a partir de la teoría del conocimiento de Kant, ha asumido la epistemología moderna. Desde el punto de vista de la epistemologia científica la razón constituye el a priori de la actividad operativa del entendimiento. Como tal, la razón es examinada y concebida, por un lado, como un sistema lógico referido al conocimiento empírico $y$ científico $y$, por otro, como un sistema operativo. tanto en un sentido mental comoen un sentido instrumental. La razón sabe a través de la lógica y la epistemologia, de sus funciones y su estructura, de sus poderes y sus límites: pero no sabe de su historia, de la genealogía que la vincula con los aspectos más elementales, más originales, de la vida humana. de la sociedado de la psicología individual.

Fue genealógica, en este sentido, la orientación señalada por Nietzsche en su crítica de la moral. Y es sugerente su camino. La moral moderna, la moral idealista fue trazada como un conjunto de leyes racionales y, por lo tanto, legitimadas porsu fuerza universal, por su vigor abstracto. $y$ no porque respondieran a una experiencia empírica de la historia, a una visión 
profunda de los conflictos y violencias de la cultura moderna. Nietzsche trató de rescatar los momentos psicológicos, los intereses individuales y colectivos, las relaciones de sumisión, de jerarquía, de coacción, en un sentido moral y estético. presupuestas, aunque ocultas en la transparencia de las máximas y leyes de la razón universal y trascendente. En la idea del deber moral, que la tradición pietista de la que se alimentó Kant más bien ligaba a las esferas celestiales de un orden universal y absoluto, La genealogía de la moralde Nietzsche descubrió una relación original de subyugación, jerarquía y opresión. Igualmente, en el universo histórico de un Estado racional y absoluto, desentrañó la pálida abstracción de una voluntad despótica y guerrera, el afán de podery el ansia de propiedad. Se abrían las puertas a una perspectiva subversiva sobre las oscuras cavernas de las idęas de la razón.

En un sentido que considero semejante, las ciencias de la religión, en obras como las de K. Kereny y, particularmente, de K. Heinrich, han estudiado genealógicamente los principios constitutivos, esto es, los orígenes de nuestra civilización. El argumento genealógico, de acuerd o con estos autores, descubre en los mitos antiguos, y en particular en los que explican los orígenes de la cultura, los principios que explican el sentido más profundo de las ciencias, de la razón moderna y sus múltiples polarizaciones. Descubrir los orígenes mitológicos de la filosofía, la ciencia y la civilización significa lo mismo que descubrir su identidad profunda. Con esto, en fin, el análisis genealógico acomete algo más que una tarea crítica, los trabajos de la conciencia negativa; además, proyecta una perspectiva emancipadora real para la filosofía, en la medida en que el descubrimiento de nuestros orígenes libera nuestra angustia frente al pasado y frente a nuestra no-identidad futura - eso que Unamuno lla mó la falta de carácter del racionalismo moderno--, y abren para la existencia las posibilidades de una nueva creatividad.

La genealogía hunde su mirada analítica en la profundidad de las experiencias y emociones humanas, de su espíritu y de su carne, que subyacen en la historia del pensamiento occidental en el logos de aquella historicidad que ha merecido el nombre de universal. De ahí que busque lo más simple, aquello que mezcla 
lo ético con el conocimiento, con el saber, olo estético con éste y con el orden moral y político. Y de ahí también que su método oscile entre el rigor analítico, y las analogías poéticas y políticas, porque su modo de razonar tiene que vincular originariamente aspectos diversos de la actividad humana, condensados en el principio de la razón, y para esto debe trazar un orden asociativo de analogías, ora lógicas, ora poéticas.

El punto de vista genealógico se distingue a su vez de la concepción histórica de la razón, de la idea de una razón histórica. Ésta presume, como muy claramente formuló Hegel, el papel fundador de la cultura, propia de la razón. Puesto que ella y sólo ella es el principio que organiza el todo de la historia bajo una orientación armónica y un objetivo final, la historia de la razón estudia la evolución de sus figuras, el relato de sus vicisitudes, la pasión de sus crisis y regresiones, y las fantásticas epopeyas que jalonan su inexorable epifanía históricosacramental. Pero no se explican ni se investigan por ese camino los orígenes, las vicisitudes y las pasiones de la cultura y la existencia humana, aquello precisamente que constituye la sombra, el lado oculto de la razón encarnada y no se describe la sustancia quebrada y escindida, el mundo que subyace al inmaculado universo de su pureza revelada de la razón. Algo semejante puede decirse de la forma modernizada de esta concepción histórica de la razón - modernizada bajo un cierto barniz positivista: la sociología del conocimiento. Ésta investiga igualmente las condiciones históricas de la ciencia y la lógica, pero no como elementos constituyentes de las figuras históricas del pensamiento o la razón, sino como figuras determinadas, condicionadas, motivadas - analógicamente hablando-por contextos históricos y sociales.

Esto no quere decir que el método genealógico no se apoye en estas concepciones históricas del pensa miento o del logos de la civilización. Pero lo hace para desentrañar, de estos nexos reales entre el espíritu y el mundo histórico, o entre la razón y las instituciones sociales en las que emergía, la estructura real de una razón que se ha definid o como sistema lógico y apriorístico. La filosofía de la historia y del derecho de Hegel, la filosofía social e histórica de Marx son ejemplos paradigmáticos de esta orientación histórica, precisamente porque reúnen, aunque no 
deduzcan las consecuencias necesarias de esto, un riquísimo material empírico que muestra, que esclarece, en el sentido más ilustrado de la palabra, la oscura genealogía del logos de la ciencia, del logos de la dominación.

Desde esta perspectiva genealógica quiero señalar dos aspectos fundamentales que definen el nacimiento del discurso filosófico europeo: su origen ascético y su impulso primario o su principio de separación. Voya considerar, a continuación, estos dos momentos por separado, basándome para ello en dos claros ejemplos de pensamiento moderno: Descartes y Hegel.

No conozco un marco más apropiado para describir, en primer lugar, lo que entiendo aquí por ascetismo que el pensamiento místico de Santa Teresa de Avila. El tema es Eros. Santa Teresa describió el proceso místico como un impulso erótico, pero que, en lugar de salir al encuentro de su objeto para participar con él en sus nupcias, se dirigía hacia lo más alto, abstracto y absoluto, es decir, la ascesis. La ascesis como vehículo de Eros, pero también como su negación. Porque en el momento culminante de la ascensión mistica de la Santa no hay amor, ni sensualidad, ni pérdida de sí mismo en la explosión de belleza, sino más bien una visión prístina, definida como un universo de cristal, puro, racional y universal: el Ser absoluto y la absoluta abstracción de todo ser. La ascesis, en su concepción mística, en el budismo, lo mismo - fundamentalmente-que en el cristianismo, es el proceso de negación, de depuración y de aniquilación de los componentes empíricos de la vida, de la existencia humana entera; es la negación de la memoria histórica, del nombre y de la biografía propios, de los sentidos y las emociones, de la sensibilidad y el erotismo, de la fantasía e incluso del entendimiento. Este proceso, que sigue, pasoa paso, metodológicamente, un camino definido de purificación, se llama iniciación. Pero la ascesis no sólo se define por aquello que niega como proceso de iniciación, sino también por sus resultados: el éxtasis del Yo y la epifanía del Espíritu absoluto. Al final del proceso místico, en efecto, Santa Teresa describe la unión mística con Dios, es decir, la identificación de sualma con su espíritu, o por utilizar más un lenguaje al estilo de este tiempo, de su ser individual y determinado, de su Yo psicológico, con un principio abstracto, racional y universal. Este espíritu puro, el 
Yo absoluto de las nupcias sagradas del alma con Dios, es la identidad asimismo absoluta que la ascesis arropa.

En la filosofía científica de Descartes el Eros es el afán universal del conocer propio de las ciencias; la iniciación mística a la visión de la verdad, la epopteia, se lla ma espíritu del método. $\mathrm{Al}$ ascetismo, a la separación interior de la conciencia, la vida y las cosas, se le llama escepticismo, y se le confunde con su sentido griego: el rigor crítico; y al éxtasis, la epifanía de un Yo puro e infinito, se le confunde ahora con la ataraxia griega, el estado de pureza y sabiduría resultante de la suspensión del juicio y de la identificación del Yo con este acto puro del juicio más abstracto, que es la negación; en fin, al Ser absoluto de la ascesis mística lo llama sujeto racional el racionalismo postcartesiano.

La analogía aquí trazada entre la filosofía científica y el ascetismo místico respeta, claro está, sus visibles diferencias. Mas, muy a pesar de ellas, la serie de negaciones espistemológicas, nacidas de la duda escéptica cartesiana, reiteran, una a una, eri su libro que no en vano exhibe el título moralista y edificante de Meditaciones, cada una de las etapas que también definen, por ejemplo, la autonegación mística de la existencia individual entera. Descartes condena epistemológicamente la memoria histórica (la tradición, las costumbres), la sensibilidad, la fantasía, la imaginación y la misma inteligencia. Al cabo de su proceso escéptico descubre la única pura actividad de la razón: la identidad lógica, $y$ fundamenta en esto el orden universal del conocimiento y el poder científicos.

La hipótesis que describo, si se quiere hablar así, puede fundar su decidida orientación crítica en otros dos exponentes de la filosofía clásica griega, en los cuales lo religioso, lo místico, e incluso lo mitológico, no se encuentran separados de lo epistemológico y filosófico en el sentid o científico de la palabra: Parménides y Platón. Parménides eleva el principio lógico de identidad a fundamento ontológico absoluto de la filosofía. Pero este principio absoluto y universal sólo puede afirmarse metafísicamente bajo la condición de negar el no-Ser y la no-identidad: la realidad particular de la vida y la experiencia humana de las cosas, en las cuales siempre la vida está unida a la muerte, el amor al odio, y donde lo real se revela más bien como 
la mezcla del ser y el no ser, algo que no posee una identidad lógica, sino que es más bien un mundo, una realidad de analogías. El orden del logos de Parménides supone asimismo una abstracción, una ascensión por encima de esta realidad, más afín a los sentidos, la fantasía, la intuición y los poetas. En Platón, a su vez, el tema de la ascensión, el abandonar el mundo de la noche y de las sombras, donde nosotros vivimos en la confusión, y en el contacto inmediato de las emociones y los cuerpos, es estilizado como la metáfora originaria del vuelo de la filosofía, la ascensión del pensamiento al reino de la luz, y de las ideas o las verdades puras. Platón describió este rito iniciático del conocimiento como separación y ascensión más allá del mundo, en uno de los mitos más fundamentales de toda la filosofía occidental: el de la caverna. Y lo formuló con aquel mismo espíritu. El reino de la epistemología, de la verdad, de la filosofía científica y del logos fue proyectado más allá de la vida, confundida con las esferas de lo oscuro y subterráneo. Pero quizás sea más fundamental aun recordar, para este propósito, el problema central del Banquete platónico, aquel que pone en directa relación el espíritu del método - la iniciación científica o mística al conocimiento racional-con Eros - la aspiracióna la belleza, al conocimiento y la creación-, en los que el espíritu está envuelto en la carne, la luz del conocimiento comparte la oscuridad del deseo, y la aspiración a la belleza es igual a la visión de un orden armónico e indefinido en el espacio y el tiempo. El Eros platónico, el impulso de la filosofía, el amor al conocimiento, sólo se satisfacen, de acuerdo con el Banquete, en la constitución de leyes racionales, ya sea como conocimiento racional de la verdad, ya sea como gobierno racional del mundo. Al final de este hermoso libro Platón no celebra, por este motivo, un canto a los amantes, o a Venus, o al mismo angélico Eupido, sino, precisa mente a Solón, héroe y legislador. $Y$ lo que media entre ambos, entre el abrazo voluptuoso del enamorado y el tribunal supremo de la razón, es, precisamente, también una forma de ascesis, la negación y divinación de la carne, la degradación de la vida humana limitada, y la elevación de su sombra espiritualizada: la luz pura del conocimiento.

Admito, una vez más, que entre el pensamiento religioso, místico y ascético, y la filosofía moderna, no hay más que 
diferencias patentes. Representan dos universos históricos autónomos. Pero aunque independientes y deslindados, no por ello deben considerarse completamente cerrados el uno al otro. En realidad, la mínima conciencia histórica lo impide, como he aludido al mostrar, casi entre paréntesis, el valor de un pensamiento como el de Parménides y Platón, entretejido con concepciones mitológicas, religiosas y filosóficas, en el moderno sentido de la palabra. Y, no obstante, debe subrayarse esta identidad más profunda, más antigua también, en los compo- . nentes morales y sensibles (éticos o estéticos) de la experiencia de la filosofía, el nacimiento de la razón.

En Parménides, por ejemplo, la búsqueda de un orden absoluto del Ser está arropada de símbolos mitológicos, y de metáforas de signo ascético. El principio lógico de identidad se yergue como el Primero de un orden absoluto de la Verdad y el Saber. Pero la postulación de esta primacía absoluta de lo lógico, y de la identidad, sólo podía cumplirse por la negación de la existencia limitada, efímera y frágil de los seres humanos y las cosas. El mundo de los seres vivos e individualizados, lo mismo que nuestra existencia, no conoce el orden de un rigor lógico, y del resplandor del Ser divino. Somos, con las cosas, mezcla de vida y muerte, claridad transida de oscuridad, mundo de ideales sublimes y de pasiones siniestras, algo que es al mismo tiempo que no es, que duda, que jadea, que se divide, y contempla el morir como parte del vivir, como parte del ser - no comoel Ser absoluto.

Qué duda cabe que el menosprecio de la propia vida por la sensibilidad y la sensualidad, o por el interés propio, y el trascender esta realidad en el universo de una identidad absoluta de la conciencia, una identidad confundida con un Ser universal, constituye el esquema, la estructura elemental y radical del proceso místico de Santa Teresa. Allí la carne es suprimida porque es efímera; el nombre y la historia propios son rescindidos por su limitáción; allí el deseo es negado en nombre de la luzy y la razón; allí, en fin, la radical conflictividad de todoser, de la vida individual lo mismo que de la historia, es superada en la medida en que se le niega el ser en un orden trascendente de ideas.

Para mostrar con imágenes más claras este elemento ascético, negador de la vida individual, inherente a la filosofía 
moderna, quiero aludir rápidamente a los ejemplos del Banquete y de la filosofía cartesiana. En el Banquete de Platón se debate el amor, pero los elementos estéticos, emocionales y poéticos del amor, tal como se dieron en la mitología griega, en los cultos de Venus y de Dionisos, o en la poesía sáfica, no aparecen en su escenario. El amor es, en Platón, lo ajeno, algo exterior y lejano, una visión desde las alturas. (En la obra de Platón, Diotima, su verdadero protagonista, porque ella y sólo ella encarna toda la sabiduría del amor, no aparece, no posee una existencia corpórea y sensible, sino que se la invoca comoa una voz lejana, profética y dogmática. Ella, la palabra del amor, adquiere una idealidad sublime, que Platón identifica con el pensar filosófico, al tiempo que pierde toda realidad sensible, $y$ por tanto expresiva, afectiva, seductora o sensual.) Define una aspiración pura, no una relación sensual, emocional e intelectual a la vez, como el amor, en realidad, es. En fin, la figura principal, entre los presentes en el banquete, es decir, Sócrates, se distingue precisamente por no participar en el ritual de los simposios antiguos: el de la ebriedad y el de la sexualidad. Es místico, en otras palabras, y profundamente ascético este libro de Platón que fundamenta el espíritu de la filosofía como ciencia, porque trasciende la existencia individual en lo sublime, y trata de fundar en su pureza apriorística el universo de un orden que, aun siendo ideal, pretende lo absoluto.

Esta dura confrontación entre la existencia individual concreta, experimentada siempre bajo un estigma negativo, y el mundo espiritual del logos, adquiere también en la obra de Descartes una bella expresión. Descartes describe en sus Meditaciones, y más acá de la elemental pero segura estructura lógica que define esta obra, un curioso malestar, una inquietud, un querer desasirse del mundo, por emplear palabras afines al mundo poético de Santa Teresa. Sus dudas sobre la limitación, la vaguedad, la irremisible falsedad de los sentidos, la fantasía, la memoria, la imaginación o la inteligencia misma, pueden comprenderse como la descripción literaria de un procedimiento científico. Sin embargo, descubre, quizás por su llamativa expresividad literaria, la reacción humana a un sentir escindido, angustiado y pesimista del mundo. La duda cartesiana no solamente es la skeptestaigriega, el principiocrítico del 
conocimiento; también es la expresión de un sentimiento de fragilidad, de falta de firmeza de la realidad inmediata en la que se vive. Descartes describe perfectamente, en las primeras meditaciones de este libro, lo que el psicoánalisis llama Kontaktangst, la angustia ante la percepción directa, por consiguiente más ligada al tacto, a los olores y colores, a la fantasía y a la imaginación, de las cosas y los cuerpos. Las mejores páginas de Descartes son por eso las que describen el metodológico nacimiento de la razón como una a rqueología de emociones, formas de experiencias, lazos y valores que su primacía cultural destruyó, lo mismo que un ejército destruye el recinto de un maravilloso poblado. La angustia cartesiana del contacto inmediato de las cosas, la angustia que confunde los sentidos, la memoria o la fantasía con el error, es, precisamente, el testigo, filosófica mente disf razado de escepticismo lógico y ontológico, de este truncamiento entre la razón y esa otra sensibilidad poética del mundo. En esta medida, la obra de Descartes muestra la razón científica como opuesta al mund o y a la vida, radicalmente arrancada y abstraída de ella; es decir, aquel mismo proceso ascético que arrancaba el espíritu a la realidad concreta de la existencia.

Quiero hacer un último comentario sobre el significadode la ascesis. Naturalmente son muchas las facetas que a este respecto se pueden mencionar. Al hablar de Santa Teresa, por ejemplo, tan sólo he señalado su lado negativo, la anihilación de sí propio, la represión de la existencia individual; no he considerado, en cambio, aquello que constituye la fuente de su riqueza literaria, de la inmersa belleza de sus escritos (como el cantar delicado de los pájaros encerrados), es decir, no me he referidoa este "retorno de lo reprimido" que siempre se abre paso en ella en sensuales, eróticas y amorosas metáforas. Pero precisamente aquí, en razón del objetivo crítico de este ensayo, debo subrayar aquel lado negativo dèl ascetismo; la ascesis como negación. desprecio y humillación de la vida, como autoaniquilación - como bien manifiestan los relatos autobiográficos de Santa Teresa - y, al mismo tiempo, como conquista intelectual de una identidad absoluta y de un Ser universal.

Este ascetismo, la voluntad de apartarse, de sesgarse de la vida y las cosas, la negación de sí mismo, ese momento de 
indiferencia o incluso de frialdad hacia lo real (combinada con una pretensión de realidad más verdadera), que definen genealógicamente los comienzos de la razón moderna, la llamo nihilismo, primera figura, interior a la constitución lógica de la razón del nihilismo. Supone esto solamente el decir que la razón definida por la filosofía científica entraña, en su condición apriorística, un principio de ind iferencia e indeferencia hacia la vida, un momento de frialdad y de dominio frente a la realidad. una negación moral y sensible de un contacto más participativo con las cosas, el mundo, en fin, más poético y más vivo de la mimesis. A esta negatividad la llamo nihilismo; la separación, en definitiva, del logos de la civilización del mundo individual, $o$. sea, lo que los místicos llamaron alma.

En segundo lugar, esta ascesis, esta negación metodológica de la vida debe ser analizada a su vez, como ya he señalado antes, en relación a sus consecuencias: el nacimiento de una identidad absoluta, el principio del Ser, el orden de una estructura lógica universal.

Ulitizo los términos de origen y resultado en su sentido más analógico. Hasta ahora he considerado el lado ascético de la razón moderna y sus consecuencius(en realidad sus premisas) nihilistas. El asunto tratado tenía que ver con la teoría del conocimiento, con la lógica; ahora hablaré de la dimensión histórica - las institliciones, las costumbres, el trabajo, los sistemas de poder - de este mismo proceso de ascensión, de progreso lógico, del discurso de la razón.

En cuanto a este discurso histórico del orden del logos, valga la redundancia, del orden del discurso de la filosofía, lo primero que quiero señalar es un elemento, que todavía no he mencionado, de aquellas ascesis, místicas ofilosóficas, inherentes a la constitución lógica de la razón. Su reino de lo sublime, el principio de la identidad y de la unión con el Ser coinciden, en un sentido a la vez moral y político, con la constitución del poder. Esto es válido tanto para el misticismo como para la filosofía científica. Estableceré, por lo pronto, una analogía, a fin de aclarar este aspecto. En la descripción del Yo absoluto, del matrimonio resultante del yo determinado y la representación del Ser absoluto, se encuentra la institución y el poder político y militar de la Iglesia católica. Está presente ese poder bajo las 
más variadas formas, desde la censura de la Inquisición y las torturas de los confesionarios, hasta la idea de una identidad universal de la cristiandad. En un sentido semejante el Yo cartesiano, el sujeto racional, está profundamente vinculado a una estructura de poder. El dominio racional -apodíctico y absoluto, como lo adjetivó el mismo Descartes - del mundo a través de su conocimiento científico estiliza, en abstractas palabras, el dominio real de los hombres o las instituciones sobre las cosas y los seres humanos. Y el sujeto racional, el agente de este conocimiento, se comporta epistemológicamente como un etéreo déspota cósmico, como en aquella orgullosa comparación que estableció Descartes entre un filósofo y un demiurgo arquimédico que movía el firmamento con unas cuantas palancas. Algunas veces se ha analizado en este sentido la relación histórica entre la constitución epistemológica del sujeto racional y la constitución político-económica del sujeto burgués: el portador social de la empresa civilizadora de dominación destructiva del universo. Y esta relación, evidentemente, existe: son dos aspectos de un mismo nexo lógico.

Santa Teresa compara el Yo místico con una fortaleza - alusión metafórica a la piedra mística de la Iglesia- y a su poder. La filosofía científica, desde Kant hasta Carnap, compara innúmeras veces el sistema de la razón con una poderosa arquitectura, o con una obra en construcción: metáfora del papel civilizador de la razón que siempre ha asumido la filosofía. Pero este nexo significa tanto como poner en estrecha interdependencia la dominación, los sistemas de poder - las fortalezas de la razón- con el ascetismo, o mejor dicho, con aquel aspecto negativo del ascetismo comprendido dentro deél como autonegación de la vida, y que se confunde con una concepción negativa o un nihilismo filosófico. Del mismo modo, con este nexo se supone una relación íntima entre el espíritu del métod o y el orden de un poder tecnológico y político que asume hasta sus plenas consecuencias el delirio filosófico de una universalidad abstracta, vacía de contenidos vitales. Y esta relación quiere decir lo siguiente: al principio racional de identidad lógica, en el que se funda la razón moderna, le es inherente la dimensión de un poder político y tecnológico de signo universal; y en consecuencia: la sublimación lógica (en 
otro tiempo la sublimación fue precisamente un proceso alquímico, a la vez místico y científico) de la existencia concreta, de la separación intectual de los seres, del abandono de todos los seres en el devenir Uno con todo el Ser, es el principio constitutivo de la dominación concebida como sistema de la historia universal. Y el nihilismo, en fin, la negación de la naturaleza limitada del ser humano, es la negativa condición ética y estética de la constitución de este poder.

He llamado a este segundo momento del análisis genealógico de la razón, y también del análisis de los componentes nihilistas intrínsecos a ella, momento de la separación. Se trata de la separación como el aspecto objetivo de la negación ascética de la vida, en cuanto ésta se contempla considerando su carácter constitutivo, fundador de poder. La palabra "separación" la empleo en un sentido afín al que define Hegel en su Fenomenología del Espiritu: como aquella abstracción lógica de la realidad que nos arranca de las cosas, y que constituye el principio de toda negatividad, del orden del concepto, de la filosofía. Hegel piensa precisamente que sólo la negación de todo Ser permite la epifanía de todo el Ser: el secreto de là dialéctica hegeliana. En ella, en su orden racional identificado con el curso histórico, el principio de la separación celebra precisamente su más alto triunfo. Pero el elemento que destaca este sentido de la separación es el arrancar, el convertir en nada, el matar; es decir, un principio de muerte como origen del logos filosófico y del papel fundador de cultura. Toda separación es una muerte metafórica. Y esta muerte es la que precisamente se encuentra muy cerca de la constitución histórica y lógica del poder. Y pone de relieve, en fin, la segunda figura del nihilismo como la dimensión de agresividad, destructividad y guerra ligada a la historia de los Estados.

No conozco un marco más apropiado para analizar este principio de separación constitutivo del poder, entendido éste como el orden universal de la razón, que la Fenomenología de Hegel El tema es ahora Thanatos. Hegel describió el ascenso histórico de la razón como un impulso hacia la separación, hacia la negación, hacia el abismo seductor de la Nada, que, sin embargo, no llegaba completamente a aniquilar su objeto, sino que lo rescataba de algún modo en un plano superior de la 
abstracción. Tal es, dicho sea entre paréntesis, un segundo aspecto de la dialéctica de Hegel. La nada, la negatividad, el principio de la muerte, se convierte con esto, lógicamente hablando, en el motor de la historia, en el fundamento del ser humano - considerado como idéntico, precisamente de acuerdo con la dialéctica, con la razón de la Historia-, en el nuevo y absoluto Ser.

Lo interesante, en $\mathrm{Hegel}$, desde la perspectiva crítica que aquí perfilo, es precisamente su identificación del logos, de la razón y la verdad con la realidad histórica y cultural. La negatividad, lo que he llamado principio de separación y de muerte, recoge en la Fenomenología hegeliana los momentos del ascetismo epistemológico que antes he considerado. La negatividad es el principio científico de la conciencia racional, para Hegel lo mismo que para Descartes. Pero esa negatividad. ese principio de muerte, está ligado, a su vez, a una realidad política y social.

La dialéctica del Señor y el Siervo es el mito de esclarecimiento filosófico más revelador en este sentido. En su concepción, Hegel aborda la tradición de la filosofía política de Hobbes e incluso del cinismo antiguo, de acuerdo con los cuales la guerra, la destrucción y la violencia eran, histórica y lógicamente hablando, los orígenes del Estado. Es cierto que Hegel critica la unilateralidad de estas concepciones, pero asume al mismo tiempo su estructura esencial. Es el tema de la muerte bajo su dimensión histórica. La dialéctica del Señor y el Siervo describe cómo el desprecio guerrero por la vida y la indiferencia heroica hacia la muerte, cómo la destrucción, la angustia y la crueldad generan el poder político, el Estado Universal que es también la Razón universal. Thanatos es concebido, aunque de manera implícita, como el motor de la historia considerada como plan racional. (Debe recordarse que ya Kant había escrito, en sus ensayos sobre la historia de la humanidad, que la guerra entrañaba un principio racional de progreso y de paz.) Pero a su vez este vínculo entre la muerte y el progreso de la historia es ocultado por la dialéctica hegeliana, en la medida en que se arropa precisamente bajo figuras particulares, como aquellas que definen el concreto proceso del desarrollo histórico. Este es el tercer momento que define la diálectica hege- 
liana. La muerte se disfraza, en Hegel, de angustia, de sentimiento de deber y obediencia; se encubre bajo la renuncia al goce, al trabajo y a la servidumbre; a parece en fin, como cualidad del sujeto moderno de la cultura. La importancia de Hegel reside precisamente, en revelar las guerras originarias, fundadoras de grandes naciones y culturas, los poderes despóticos, y el mismo reino de terror y amenaza, como un impulso que contiene, en su raíz, la dimensión racional de la cultura y la libertad humana.

He considerado dos aspectos, dos momentos de la genealogía de la razón y su proyección cultural. El primeroentrañaba un sentido intelectual, moral y estético; el segundo posee un aspecto histórico y social; tiene que ver con la realidad objetiva de instituciones, de la violencia social o del discurso de la guerra.

Uno entrañaba el proceso de ascesis, de sublimación de la realidad, y junto con el otro de negación de la vida, de autonegación del ser en la misma experiencia filosófica o moral que prentendía abarcar el Ser. En el segundo momento, esta ascesis adquiere la forma individualizada de la separación, de la crueldad, de la indiferencia y desprecio guerreros de la vida. En el primer caso el nihilismo se revelaba como un componente pulsional de la misma constitución de la razón moderna y del sujeto racional humano. La razón, el logos de la civilización, descubre así su carácter negativo y nihilista como su virtud sensible y moral. Bajo la segunda perspectiva histórica este nihilismo adquiere las connotaciones, más cercanas a lo político, del despotismo y la humillación, la destrucción y la sumisión moral. Pero, además, la ascesis filosófica del logos está vinculada originariamente a una deformación, a una transformación negativa de un impulso amoroso que el pensamiento de los antiguos relacionó con el amor individual, con la aspiración a la belleza, al placer. El segund o momento remite, a su vez, a un primario impulso negativo, un afán de poder y de destrucción, de competitividad y de guerra. Este trasfondo de la genealogía de la razón bajo el aspecto de la ascesis y la separación remonta, de hecho, a las concepciones del mundo de mitologías antiguas, como la cosmogonía de Hesiodo o la física de Lucrecio, que parten precisamente de Eros y la discordia como potencias primarias. Pero, atendiendo a nuestra cultura 
contemporánea, la definición de este nexo es algo que no puede hacerse sin una referencia al análisis de la cultura de Freud. Voy a dedicar a ello unas palabras; voy a dedicarlas, más particularmente, al tema de la relación entre Eros y Thanatos.

Freud y algunos de sus discípulos, como Fenichel y Reich, analizaron los elementos constitutivos de la cultura bajo la perspectiva de dos principios originarios: Eros y Thanatos, el impulso del amor y la creación y el impulso de la destrucción. Desde el punto de vista del primero observó el fenómeno elemental que llamó sublimación, una palabra que en su obra recoge precisamente elementos del sublimado alquimista (la purificación ascética que al mismo tiempo es el descubrimiento científico del orden racional de las cosas) y el concepto filosófico y místico de lo sublime: la esfera intelectual de las ideas puras. En el análisis de la sublimación cultural de las pulsiones humanas, Freud establece, a su vez, un nexo entre la frustración instintiva, es decir, los aspectos de la negación ascética de la vida, y la racionaíización, la sustitución y el ocultamiento (la represión, en lenguaje de Freud) de este proceso real de anihilación por una construcción, un orden racional. Freud definió la cultura, la genealogía y la historia cultural, el progreso, en fin, como un proceso de sublimación - de hecho esto es una vieja concepción. Pero al hacerlo (y en ello reside la originalidad de la teoría psicoanalítica de la cultura) ponía de manifiesto el vínculo interior de la constitución del orden cultural con la negación (instintiva) de la persona y la experiencia individual de la vida y, asimismo, con la racionalización, es decir, el ocultamiento de aquella vida reprimida y su sustitución por su réplica ideal, el mundo filosófico del discurso. Que Freud empleara la palabra "racionalización" para develar un proceso de ocultamiento de la realidad de la existencia a través de la conciencia racional, posee en sí mismo un enorme interés (y un interés algo irónico también), porque la racionalización, en el mundo del pensamiento filosófico y sociológico contemporáneo, al nacimiento del psicoanálisis, designaba más bien el progreso cultural hacia formas de vida, de comunicación y de creación cada vez más homogeneizadas con arreglo a un paradigma lógico y tecnológico, o instrumental. Freud rompedrásticamente con la pretensión teórica de consistencia moral y psicológica de la 
conciencia o de las premisas lógicas de aquella concepción racionalista de la historia.

La teoría de la cultura de Freud, lo mismo que la perspectıva sobre la genealogía de la razón histórica esbozada en estas páginas, es conflictiva, y ha tendido a ser desplazada por este carácter inconciliatorio de las formas más oficiales de la cultura de masas y de la cultura intelectual. Se asume precisamente bajo su visión la radical conflictividad de la condición histórica del hombre moderno. $Y$ las consecuencias de esta radicalidad intelectual no son precisamente pequeñas. Pero quiero referirme ahora al segundo aspecto, al principio de la muerte. Es sugerente notar, en el caso de Freud, que la asunción teórica y sistematizada de la condición escindida y conflictiva del ser humano (eso que tanto furor causó a los pálidos humanistas de nuestro tiempo), no le permitía todavía comprender la agresividad social, la destructividad de nuestra civilización, y la violencia de explosiones sociales y guerras. Y Freud tuvo que admitir, con enormes reticencias morales y teóricas, un principio originario de agresión y de muerte que, aun siendo vagamente subsidiario del gran Demón y del gran seductor Eros, era capaz de limitar y destruir con sus poderes los lazos de aquél. Por consiguiente, había que admitir, - hay que admitir- la existencia de un principio originario de guerra y de destrucción.

Ya he hablado anteriormente de este anhelo de la separación concretamente cumplido en el desafío a la muerte que constituye el principio en el que el héroe asienta su dominación despótica en nombre de la virtud moral y en nombre del terror que ejerce. Freud no trata en este sentido sino de introducirnos en la profundidad psicológica y mitológica de este principio lógico y social (o histórico-racional, para hablar como los grandes filósofos del idealismo moderno) de la separación y de la muerte. Pero, al mismo tiempo, Freud analizó con mucha claridad el nexo que existe entre la sublimación cultural y el principio de destrucción. Podrá otorgarse a éste último el derecho a un poder universal y autónomo, encerrado emblemáticamente en un idealizado Thanatos. (Este fue el tema que criticaron Fenichel y, sobre todo, W. Reich, a través, precisamente, de un análisis crítico de la civilización y sus conflictos.) Pero aún observando la autonomía de un instinto destructivo, 
el Psicoanálisis mostró un vínculo profundo entre éste y la sublimación cultural del hombre moderno. Bajo las condiciones de conflictividad, de frustración y, por tanto, de autodestrucción, que caracterizan a la cultura moderna, lo mismo en un plano económico que moral y vital, la sublimación revela amargamente todos sus lados negativos; pues bajo ellos se alimenta la indiferencia a la vida; la frialdad, la muerte interior, el juego perverso de nuestras ciencias y nuestros instrumentos con la muerte, y se genera la misma idea racional de la guerra.

Nuestra cultura trabaja en favor de la muerte. Niega la vida bajo las exigencias de la sublimación, y afirma la muerteen la conciencia de su separación irremisible de la naturaleza y la vida. La cultura se vive como la más honda crisis. Se adivinan los factores de su fin.

A esta concepción de la genealogía de la razón y de los conflictos de la civilización se le podrá llamar pesimista. De hecho se ha calificado de pesimista la visión que de la historia tenía Freud. Pero en realidad eso solamente fue, y es así, porque es más fácil conformarse con el lado resignado de las cosas, en lugar de extraer sus últimas y radicales consecuencias, y cambiar en consonancia con esto nuestras voluntades y nuestras formas de pensamiento dominantes. En realidad estas perspectivas teóricas perfilan un horizonte muy distinto. A través deél, se traza, aunque de manera teórica, un límite a la historia de la cultura moderna y a sus fundamentos filosóficos, artísticos y religiosos. He tratado de relatar la historia de la conflictiva condición del hombre moderno; lo he intentado buscando algunos rastros de la genealogía de su principio lógico, es decir, la idea de razón. He mostrado, a través de algunos ejemplos de la psicología, del arte y la filosofía, el fundamento negativo que subyace en esta conflictividad: la autoanihilación ascética que subyace al principio de la razón; y he señalado, con otras menciones, la tendencia profunda hacia la destrucción y hacia la guerra que necesaria, aunque falsamente, genera aquella conflictividad y tensión interiores al sujeto humano y a nuestra cultura objetivamente considerada.

Eso nos ayuda ahora a responder, aunque un tanto oblicuamente, a la pregunta formulada al principio: ¿Puede el progreso histórico seguir su camino de sacrificios humanos? 
$¿$ Tiene la historia - y la vida humana en aquellos aspectos que dependen de ella - algún sentido? La respuesta que he dado es ciertamente compleja y difícil. Ya he dicho que es oblicua, indirecta $y$, ciertamente, inacabada. Por ser negativa, traza un análisis crítico y dibuja el perfil de una teoría negativa de la cultura. Este espíritu negativo, sin embargo -y lo repito de nuevo - , no se confunde en modo alguno con el pesimismo. No cabe duda que el pesimismo histórico constituye la condición emocional cotidiana de nuestras vidas. Pero la filosofía, la reflexión teórica debe hacer precisamente un esfuerzo ejemplar por sobreponerse a esta condición espiritual de nuestro tiempo. El pensamiento asume esta dimensión positiva, incluso allí donde trata de formular - aunque sólo sea tímidamente - una orientación en el mundo, es decir, un horizonte, y el perfil de una dirección hacia donde encaminarse. La perspectiva crítica en este sentido encierra una profunda dimensión positiva, creadora de futuro y en definitiva utópica. Toda negación de lo pequeño y limitado, de las cosas de nuestro mund o finito - no la crítica del gran No absoluto-encierra un gran Sí, la voluntad, apenas confesada algunas veces, de dar forma a una nueva esperanza. Esa aspiración es como la sombra que arrojar ${ }_{2}$ las luces, hoy necesariamente oscuras, del análisis genealógico de la razón y de la historia de la civilización. 